Краткие сообщения / Short communications

https://doi.org/10.18619/2072-9146-2020-3-36-38 УДК 635.646:631.542.32:631.544.4

Терехова В.И., Константинович А.В.

Федеральное государственное бюджетное образовательное учреждение высшего образования «Российский государственный аграрный университет - МСХА имени К.А. Тимирязева (ФГБОУ ВО РГАУ-МСХА имени К.А. Тимирязева) 127550, Россия, г. Москва,

Тимирязевская ул., 49

E-mail: vterechova@yandex.ru, rumexred@gmail.com

Конфликт интересов: Авторы заявляют об отсутствии конфликта интересов.

Для цитирования: Терехова В.И., Константинович А.В. Влияние типов формирования растений баклажана на урожайность в условиях летне-осеннего оборота в пленочных теплицах. Овощи России 2020;(3): 36-38. https://doi.org/10.18619/2072 9146-2020-3-36-38

Поступила в редакцию: 10.04.2020

Принята к печати: 24.05.2020

Опубликована: 25.07.2020

Vera I. Terekhova

Anastasiya V. Konstantinovich

Russian State Agrarian University - Moscow

Timiryazev Agricultural Academy

49, Timiryazevskaya St., Moscow, 127550, Russia

E-mail: vterechova@yandex.ru,

rumexred@gmail.com

Conflict of interest: The authors declare no conflict of interest.

For citation: Terekhova V.I., Konstantinovich A.V. Influence of types of eggplant plant formation on productivity in the conditions of summer-autumn turnover in film greenhouses. Vegetable crops of Russia. 2020;(3):36-38. (In Russ.)

https://doi.org/10.18619/2072-9146-2020-3-36-38

Received: 10.04 .2020

Accepted for publication: 24.05 .2020

Accepted: 25.07 .2020
Влияние Типов формирования растений баклажана на урожайность в условиях летне-осеннего
оборота в пленочных теплицах

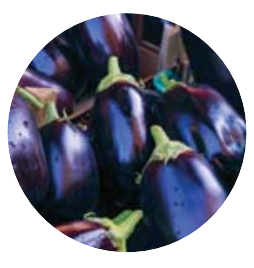

РЕЗЮМЕ

Актуальность. Ежегодное увеличение площадей под культурой баклажана в малых фермерских хозяйствах и индивидуальном секторе объясняется высокими питательными, диетическими, вкусовыми качествами, а также многоцелевым использованием плодов. Для оптимального роста и развития баклажану необходима высокая сумма активных температур, что сильно ограничивает выращивание культуры во многих регионах России. Однако зону выращивания баклажана расширяют за счёт использования промышленных и пленочных необогреваемых теплиц. Разработка элементов технологии выращивания баклажана в пленочных теплицах является актуальной, так как способствует увеличению площадей в фермерских хозяйствах.

Материал и методы. Целью исследований являлось обоснование элементов технологии выращивания баклажана в пленочных необогреваемых грунтовых теплицах. Исследования проводили в 2018-2019 годах на базе Учебно-научно производственного центра "Овощная опытная станция им. В.И. Эдельштейна" РГАУ-МСХА имени К.А. Тимирязева в летне-осеннем обороте в пленочной необогреваемой грунтовой теплице. Объектами исследования являлись сорта и $F_{1}$ гибриды баклажана: $F_{1}$ Боровичок, $F_{1}$ Багира, F1 Нежнейший, F1 Патио Трио, в качестве контроля использовали гибрид $F_{1}$ Пеликан; сорта баклажана: Грибное удовольствие, Черный красавец, Дон Кихот, в качестве контроля использовали сорт Франт.

Результаты. В целом по итогам изучения влияния формирования сортов и гибридов баклажана в два и три стебля на общую урожайность в условиях летне-осеннего оборота в пленочных грунтовых теплицах рекомендуем выращивать все изученные гибриды и сорта в три побега.

Ключевые слова: гибриды и сорта баклажана, летне-осенний оборот, урожайность, пленочные теплицы, формирование растений.

\section{Influence of types of eggplant plant formation on productivity in the conditions of summer-autumn turnover in film greenhouses}

\section{ABSTRACT}

Relevance. The annual increase in the area under the eggplant culture in small farms and the individual sector is explained by high nutritional, dietary, taste, and also the multi-purpose use of fruits. For optimal growth and development, eggplant needs a high amount of active temperature, which greatly limits the cultivation of crops in many regions of Russia. However, the eggplant growing area is expanded through the use of industrial and film unheated greenhouses. The development of technology elements for growing eggplant in film greenhouses is relevant, as it contributes to an increase in the area of farms.

Materials and methods. The aim of the research was to substantiate the elements of the technology for growing eggplant in film unheated soil greenhouses. The studies were carried out in 2018-2019 at the base of the Educational and Scientific Production Center "Vegetable Experimental Station named after IN AND. Edelstein" RGAU-Moscow Agricultural Academy named after K.A. Timiryazev in the summer-autumn turnover in a film unheated soil greenhouse. The objects of research were varieties and $F_{1}$ eggplant hybrids: $F_{1}$ Borovichok, $F_{1}$ Bagira, $F_{1}$ Tender, $F_{1}$ Patio Trio, as a control they used a hybrid $F_{1}$ Pelican; eggplant varieties: Mushroom pleasure, Black handsome, Don Quixote, they used the Frant variety as a control. Results. In general, based on the results of studying the influence of the formation of two and three stalked eggplant varieties and hybrids on the total yield in the conditions of summerautumn turnover in film soil greenhouses, we recommend that all studied hybrids and varieties be grown in three shoots

Keywords: hybrids and varieties of eggplant, summer-autumn turnover, productivity, film greenhouses, plant formation. 
Введение

реди овощных культур из семейства Пасленовые баклажан занимает особое место. Ежегодное увеличение площадей под культурой баклажана в малых фермерских хозяйствах и индивидуальном секторе объясняется высокими питательными, диетическими, вкусовыми качествами, а также многоцелевым использованием плодов [1,2]. По данным Государственного реестра селекционных достижений, допущенных к использованию в 2019 году на территории Российской Федерации, районировано более 200 сортов и гибридов баклажана [3].

Особая ценность плодов баклажана определяется вкусовыми и диетическими свойствами, содержанием ценных компонентов и ароматических веществ. Терпкий вкус плодов баклажана обусловлен наличием пектиновых, дубильных веществ, гликоалколоидом соланином М [2].

В плодах баклажана содержится 7-11\% сухого вещества, 2,54\% сахаров, 0,6-1,4\% белков, 0,1-0,4\% жиров [1,4]. Среднее содержание макро- и микроэлементов: К - 210 мг/100 г, Са - 10 мг/100 г, Mg - 11 мг/100 г, P - 16 мг/100 г. Макроэлемент калий нормализует сердечную деятельность водно-солевого обмена, способствует щелочному равновесию в организме [5].

Баклажаны популярны в кулинарии многих стран мира, так как их жарят, запекают, тушат, солят, сушат, используют для приготовления икры, закусок, салатов и т.п. Не рекомендуется употреблять в пищу сырые баклажаны [4].

Для оптимального роста и развития растению баклажана необходима высокая сумма активных температур, что сильно ограничивает выращивание культуры во многих регионах России. Основные зонь выращивания баклажана в открытом грунте - юг России, Северный Кавказ. Однако зону выращивания баклажана расширяют за счёт использования промышленных теплиц и пленочных необогреваемых. Разработка элементов технологии выращивания баклажана в пленочных теплицах является актуальной, так как будет способствовать увеличению площадей в фермерских хозяйствах

Цель исследований - обоснование элементов технологии выращивания баклажана в пленочных необогреваемых грунтовых теплицах.

\section{Методика, объекты}

и условия проведения исследований

Научные исследования проводили в 2018-2019 годах на базе Учебно-научно производственного центра «Овощная опытная станция им. В.И. Эдельштейна» РГАУ-МСХА имени К.А.Тимирязева в летне-осеннем обороте в пленочной необогреваемой грунтовой теплице.

Исследования проведены в соответствии с общепринятыми рекомендациями для овощных культур в защищенном грунте $[6,7,8]$. Опыт закладывали в 3-х кратной повторности, площадь учётной делянки 3,3 м². Учёт урожая проводили в динамике, взвешиванием плодов с каждой делянки при каждом сборе, с последующим пересчётом в килограммы с 1 м2 [6,7].

Объектами исследования являлись сорта и $\mathrm{F}_{1}$ гибриды баклажана: $F_{1}$ Боровичок, F1 Багира, $F_{1}$ Нежнейший, $F_{1}$ Патио Трио, в качестве контроля использовали гибрид $\mathrm{F}_{1}$ Пеликан; сорта баклажана: Грибное удовольствие, Черный красавец, Дон Кихот, в качестве контроля использовали сорт Франт.

Агротехника в опыте:

Рассаду выращивали в рассадном отделении многорядной

Таблица 1. Ранжирование сортов и гибридов баклажана по группам спелости в условиях летне-осеннего оборота в пленочных грунтовых теплицах (среднее за 2018-2019гг)

Table 1. Variety ranking and flexibility by group characteristics in the conditions of summer-autumn gates in film soil greenhouses (average value for 2018-2019)

$$
\text { Доля сортов и гибридов, \% }
$$

\section{Группа спелости, сутки}

До 110 суток

До 120 суток

До 130 суток

Всего

\begin{tabular}{l} 
два стебля \\
\hline шт.
\end{tabular}

5

3

1

9 три стебля

шт.

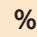

55,6

33,3

11,1

100
5

4

9
55,6

44,4

100 теплицы серии Ришель 9,6 SR. Посев семян произвели 14-15 марта 2018-2019 годов, срок ликвидации растений - 15-16 сентября 2018-2019 годов.

Сеянцы выращивали в верховом торфе в кассетах с размером ячейки 5 × 5 × 5 см и с ее объемом 125 см3. Всходы отмечали на 8-12 день после посева. Перевалку проводили на 20 сутки от всходов в горшки объемом 0,8 л. В момент смыкания листьев проводили однократную расстановку рассады до 20 раст./м². Среднесуточные температуры устанавливали согласно состоянию растений и графику.

Перед высадкой рассады почва в теплице была замульчирована черным нетканным материалом. В пленочную необогреваемую теплицу рассаду высаживали 21-22 мая, период выращивания рассады 55 суток. Густота стояния растений - 2,5 раст./м². После высадки растений в теплицу подвешивали шпагат и 2 раза в неделю подкручивали стебель. Применяли систему формирования растений в 2 и 3 стебля.

Подкормки проводили комплексным удобрением Yara Kristalon 18.18.18+3 с интервалом в 5 суток: первую подкормку провели - через 5 суток после высадки рассады.

Обработку пестицидами проводили при выявлении единичных очагов заражения: против грибных заболеваний - Ридомил МЦ Голд, ВДГ (д.в. манкоцеб + мефеноксам) и Квадрис, КС (д.в. азоксистробин). В течение периода вегетации проводили поливы дождеванием. При повышении температуры в теплице выше $30^{\circ} \mathrm{C}$ применяли освежительные поливы.

\section{Результаты и обсуждение}

Производители окончательные выводы о выращивании того или иного сорта или гибрида делают в хозяйстве на основании нескольких показателей. Одними из ключевых показателей для выращивания баклажана в пленочных теплицах являются раннеспелость и урожайность

Изучая формирование сортов и гибридов баклажана в два и три стебля на раннеспелость и общую урожайность в результате проведенных исследований нами были выявлены структурные изменения по продолжительности периода «массовые всходы - техни ческая спелость». При формировании в два стебля большинство сортов и гибридов $(55,6 \%)$ относились к группе среднеранних, т.е. период «массовые всходы - техническая спелость» составлял до 110 суток, к группе средних относилось - 33,3\%, период «массовые всходы - техническая спелость» составлял до 120 суток (табл.1). Однако при формировании растений баклажана в три стебля изучаемые сорта и гибриды имели более продолжительный период «массовые всходы - техническая спелость», что привело к перераспределению внутри групп спелости. В группу средних было отнесено 55,6 \% изучаемых сортов и гибридов и в группу поздних - 44,4\%.

В условиях пленочных необогреваемых грунтовых теплиц при формировании гибридов баклажана в 2 и 3 стебля по ранней и общей урожайности следует отметить, что изучаемые гибриды не превзошли контрольный гибрид $\mathrm{F}_{1}$ Пеликан (табл.2).

При формировании в 2 стебля по ранней урожайности гибрид

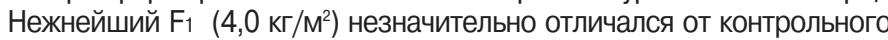

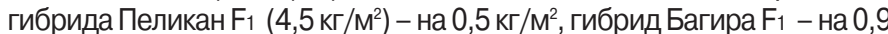

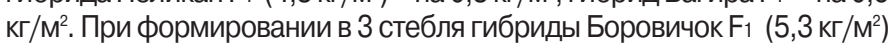
и Багира $F_{1} \quad(5,4$ кг/M²) не превзошли по ранней урожайности контрольный гибрид, но имели урожайность, не существенно отличающуюся от контроля, что подтверждено результатами статистической обработки (табл.2), соответственно ранняя урожайность Боровичок F

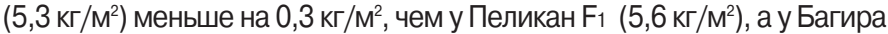

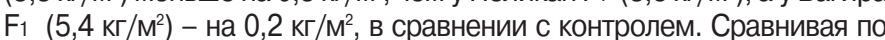
общей урожайности изучаемые гибриды, следует выделить гибрид Багира F1 (9,6 кг/м²), который в сравнении со всеми остальными гибридами имел при формировании в 2 стебля урожайность чуть ниже

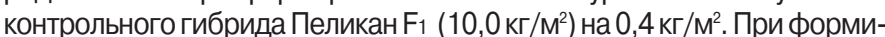
ровании растений баклажана в 3 стебля все исследуемые гибриды имели достоверные различия по урожайности с контрольным гибридом Пеликан $\mathrm{F}_{1}$ (12,7 кг/м²). Во всех изученных способах формирования растений наименьшая ранняя и общая урожайность были отмечены у гибрида Патио Трио F1 (табл.2), что связано с небольшой массой плодов в сравнении с другими гибридами (табл.3).

Сравнивая раннюю и общую урожайность исследуемых сортов баклажана при формировании растений в 2 и 3 стебля в условиях пленочных необогреваемых грунтовых теплиц, по ранней и общей урожайности следует выделить сорт Грибное удовольствие, который 
Таблица 2. Влияние формирования сортов и гибридов баклажана в два и три стебля на раннюю и общую урожайность в условиях летне-осеннего оборота в пленочных грунтовых теплицах (среднее за 2018-2019 годы)

Table 2. The effect of the formation of two and three stalked eggplant varieties and hybrids on early and total productivity in the summer-autumn turnover in film greenhouses (average for 2018-2019)

Гибриды и сорта

Пеликан $\mathrm{F}_{1}$ - st

Боровичок $F_{1}$

Багира $\mathbf{F}_{1}$

Нежнейший $F_{1}$

Патио Трио F1

$\mathrm{HCP}_{05}$

Франт - st

Грибное удовольствие

Черный красавец

Дон Кихот

$\mathrm{HCP}_{05}$
Ранняя урожайность, $\mathrm{kr} / \mathrm{M}^{2}$

\section{2 стебля}

4,5

3,2

3,6

4,0

2,6

0,9

2,5

3,1

2,7

1,5

0,7

\section{3 стебля}

5,6

5,3

5,4

4,7

3,4

0,7

3,8

4,9

3,6

3,3

0,6
Общая урожайность, $\mathrm{kr} / \mathrm{M}^{2}$

2 стебля

10,0
8,4
9,6
8,1
7,2
1,1
5,9
7,3
6,3
4,5
1,7

3 стебля

12,7

10,0

10,8

9,4

8,4

1,6

9,0

11,1

7,3

6,7

1,5

Таблица 3. Влияние формирования сортов и гибридов баклажана в два и три стебля на выход товарной и массу плода в условиях летне-осеннего оборота в пленочных грунтовых теплицах (среднее за 2018-2019 годы)

Table 3. The effect of the formation of eggplant varieties and hybrids in two and three stems on the yield of the commodity and the mass of the fruit in the conditions of summer-autumn turnover in film soil greenhouses (average for 2018-2019)

Гибриды и сорта

\begin{tabular}{|l|l|}
\hline Пеликан $\mathrm{F}_{1}$ - st \\
\hline Боровичок $\mathrm{F}_{1}$ \\
\hline Багира $\mathrm{F}_{1}$ \\
\hline Нежнейший $\mathrm{F}_{1}$ \\
\hline Патио Трио $\mathrm{F}_{1}$ \\
\hline HСР 05 \\
\hline Франт - st \\
\hline Грибное удовольствие \\
\hline Черный красавец \\
\hline Дон Кихот \\
\hline НСР
\end{tabular}

превосходил контроль Франт во всех вариантах (табл.2). Сорт Грибное удовольствие $\left(3,1 \mathrm{\kappa} / \mathrm{M}^{2}\right)$ по ранней урожайности превысил

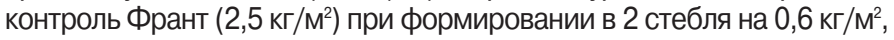
при формировании в 3 стебля сорт Грибное удовольствие $\left(4,9 \mathrm{\kappa r} / \mathrm{M}^{2}\right)$ по ранней урожайности превысил контроль Франт (3,8 кг/м²) на 1,1 кг/М². По общей урожайности сорт Грибное удовольствие $\left(7,3 \mathrm{kг} / \mathrm{M}^{2}\right)$ превысил контрольный сорт Франт (5,9 кг/м²) при формировании в 2

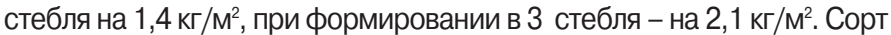
Черный красавец при формировании растений в 2 побега по ранней

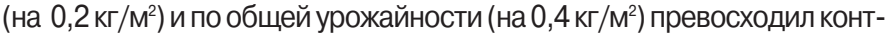
роль Франт, но имел худшую урожайность в сравнении с контролем Франт при формировании в 3 стебля как по ранней (на 0,2 кг/м²), так и по общей урожайности - на 1,7 кг/М² (табл.2).

\section{Об авторах:}

Терехова Вера Ивановна - кандидат с.-х. наук,

доцент, доцент кафедры овощеводства

Константинович Анастасия Владимировна - кандидат с.-х. наук,

доцент, зав. кафедрой овощеводства

\section{- Литература}

1. Мешков А.В., Терехова В.И., Константинович А.В. Практикум по овощеводству: учебное пособие. СПб.: Издательство "Лань», 2017. 292 c.

2. Тараканов Г.И., Мухин В.Д., Шуин К.А. и др. Овощеводство. 2-е изд. Перераб. И доп. М.: Колос, 2002. $472 \mathrm{c}$

3. ФГБУ «Госсорткомиссия» - http://reestr.gossortrf.ru/reestr.htm

4. Бунин М.С. Мешков А.В., Терехова В.И.. Константинович А.В. Овощи мира. Ӭнциклопедия мировых биологических ресурсов овощОвощи мира. Энциклопедия мировых биологических ресурсов ово

5. Голубкина Н.А., Сирота С.М., Пивоваров В.Ф., Яшин А.Я. Я Яшин 5. олубкина Н.А., Сирота С.М., Пивоваров В.Ф., ' Мшин А.Я ̈̈ Ашин Я.И. Биологически
СОК, 2010. 200 с.

6. Методика опытного дела в овощеводстве и бахчеводстве. М: Агропромиздат, 1992 . 319 с.

7. Ващенко С.Ф., Набатова Т.А. Методические рекомендации по проведению опытов с овощными культурами в сооружениях защищенного грунта. М.: ВАСХНИЛ, 1976.

8. Агапов А. С. и др. Методические указания по селекции сортов и гибридов перца, баклажана для открытого и защищенного грунта. Рос. акад. с.-х. наук, Всерос. науч.-исслед. ин-т селекции и семеноводства овощных культур. М.: 1997. 88 с.

\begin{tabular}{|c|c|}
\hline \multicolumn{3}{|c|}{ Масса плода, $\mathbf{~}$} \\
\hline 2 стебля & 3 стебля \\
\hline 200 & 188 \\
\hline 185 & 180 \\
\hline 180 & 170 \\
\hline 200 & 180 \\
\hline 120 & 120 \\
\hline 17,1 & 15,9 \\
\hline 180 & 172 \\
\hline 220 & 210 \\
\hline 180 & 163 \\
\hline 150 & 140 \\
\hline 16,5 & 10,85 \\
\hline
\end{tabular}

В результате изучения влияния формирования сортов и гибридов баклажана в два и три стебля на массу плодов нами было отмечено, что формирование сортов и гибридов баклажана в три стебля приводило к небольшому снижению массы плодов исследуемых гибридов, за исключением Патио Трио F1 (табл.3) .

\section{Заключение}

Исследования показали перспективность использования способов формирования в два и три стебля. По итогам изучения влияния формирования сортов и гибридов баклажана в два и три стебля на общую урожайность в условиях летне-осеннего оборота в пленочных грунтовых теплицах рекомендуем выращивать все изученные гибриды и сорта в три побега.

\section{About the authors:}

Vera I. Terekhova - Cand. Sci. (Agriculture),

associate professor vegetable growing chair

Anastasiya V. Konstantinovich - Cand. Sci. (Agriculture),

associate professor, head of vegetable growing chair

\section{- References}

1. Meshkov A.V., Terekhova V.I., Konstantinovich A.V. Horticulture Workshop: study guide. St. Petersburg: Publishing House "Lan", 2017.

292 p. (In Russ.) Kolos, 2002. 472 p. (In Russ.)

3. FSB "State Commission" - http://reestr.gossortrf.ru/reestr.html 4. Bunin M.S., Meshkov A.V., Terekhova V.I., Konstantinovich A.V. Vegetables of the world. Encyclopedia of world biological resources of
vegetable plants. M.: GNU TSNSHB Rosselkhozakademii, 2013. 496 p. (In

Russ.)
5. Golubkina N.A., Sirota S.M., Pivovarov V.F. Yashin A.Ya. Yashin Y.I.

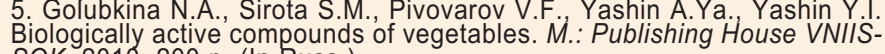
SOK, 2010.200 p. (In Russ.)

6. Methodology of experimental work in vegetable growing and melon growing. Edited by V.F. Belika. M: Agropromizdat, 1992. 319 p. (In Russ.) 7. Vashchenko S.F., Nabatova T.A. Guidelines for conducting experiments with vegetable crops in the construction of sheltered soil. M.: VASKHNIL, 1976. (ln Russ.)

8. Agapov A.S. et al. Guidelines for the selection of varieties and hybrids of pepper, eggplant for open and protected ground. M.: 1997. 88 p. (In Russ.) 